\title{
Simultaneous management of congenital tracheal stenosis and cardiac anomalies in infants
}

\author{
Tsvetomir Loukanov, MD, ${ }^{\text {a }}$ Christian Sebening, MD, ${ }^{\text {a }}$ Wolfgang Springer, MD, ${ }^{\mathrm{b}}$ Herbert Ulmer, MD, PhD,
} and Siegfried Hagl, MD, $\mathrm{PhD}^{\mathrm{a}}$

From the Departments of Cardiac Surgery ${ }^{\mathrm{a}}$ and Paediatric Cardiology, ${ }^{\mathrm{b}}$ University of Heidelberg, Heidelberg, Germany.

Received for publication June 5, 2005; revisions received July 8, 2005; accepted for publication Aug 23, 2005.

Address for reprints: Tsvetomir Loukanov, MD, Department of Cardiac Surgery, Surgical Clinic, INF 110, 69120 Heidelberg, Germany (E-mail: tsloukanov@abv.bg).

J Thorac Cardiovasc Surg 2005;130:1537-41

$0022-5223 / \$ 30.00$

Copyright $\odot 2005$ by The American Association for Thoracic Surgery

doi:10.1016/j.jtcvs.2005.08.031
Objective: The present article aims to describe our experience with patients who underwent simultaneous repair of congenital tracheal stenosis and cardiac anomalies.

Methods: Between January 2000 and December 2003, 9 infants underwent simultaneous surgical repair of a congenital tracheal stenosis and congenital heart disease. The intraoperative findings revealed localized tracheal stenosis in 3 patients. The funnel-type tracheal stenosis was present in 6 patients. Associated cardiac anomalies included ostium secundum atrial septal defect in 5 patients and ventricular septal defect in 2 patients, pulmonary artery sling in 4 patients, patent ductus arteriosus in 6 patients, atrioventricular septal defect in 1 patient, aortic arch hypoplasia in 1 patient, coarctation of the aorta in 1 patient, and partial anomalous pulmonary venous connection in 2 patients, one of them with "scimitar syndrome." Tracheal origin of the right upper lobe was diagnosed in 2 of the patients. A right aberrant subclavian artery (lusoria) was found in one patient. All patients were operated on through a median sternotomy and with cardiopulmonary bypass. Tracheal resection with direct end-to-end anastomosis was performed in all cases.

Results: There was no operative mortality. One patient died 6 weeks postoperatively. Eight patients were extubated between the 14th and 30th postoperative days under bronchoscopic monitoring. The extubation was performed after a stepwise respirator-weaning program. Postoperative endoscopic examination showed adequate airway dimensions and patency in every case. The midterm results after a mean follow-up of 37 months (range, 16-58 months) of the entire group demonstrate a stabile and complication-free clinical outcome.

Conclusions: We advocate our current strategy for infants with congenital tracheal stenosis: resection with end-to-end anastomosis and simultaneous repair of associated intracardiac anomalies.

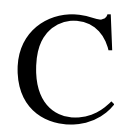
ongenital tracheal stenosis (CTS) in neonates and infants is an underdiagnosed, life-threatening respiratory anomaly. The combination of the rarity of the lesion, the small size of the pediatric airway, and the lesser tolerance of the infantile trachea for anastomotic tension has hindered the development of pediatric tracheal operations. ${ }^{1}$

The absence of the membranous portion of the trachea might create local or generalized stenosis. ${ }^{2}$ Backer and Mavroudis ${ }^{3}$ defined tracheal stenosis as a reduction in the anatomic luminal diameter of the trachea by more than $50 \%$ of the remaining normal trachea. They classified tracheal stenosis as follows: congenitalcomplete tracheal rings; postintubation; traumatic; congenital web, and other. Tracheal stenosis is further divided into localized $(<50 \%$ tracheal length) and longsegment $(>50 \%)$ stenosis. Complete cartilaginous O-rings are the most common macroscopic finding. ${ }^{4}$ 

Abbreviations and Acronyms
ASD = atrial septal defect
AVSD $=$ atrioventricular septal defect
$\mathrm{CPB}=$ cardiopulmonary bypass
CTS = congenital tracheal stenosis
LPA $=$ left pulmonary artery
PA = pulmonary artery
VSD $=$ ventricular septal defect

In the largest series reporting on pulmonary artery (PA) sling, $58 \%$ of the patients had associated complete tracheal rings. ${ }^{5}$ The ideal treatment of long-segment CTS associated with complete tracheal rings remains controversial.

Different surgical alternatives have been suggested for long-segment CTS, such as pericardial, cartilage, or slide tracheoplasty; free tracheal homografts or autografts; and external stabilization in case of long-segment tracheobronchomalacia. ${ }^{6,7}$

Associated congenital cardiac malformations are diagnosed often in this group of patients. They are represented mostly by ventricular septal defect (VSD) and atrial septal defect (ASD). Some of the more complicated congenital heart malformations can also accompany CTS: atrioventricular septal defects (AVSDs) and "scimitar syndrome."

The present article aims to describe our experience with 9 patients who had simultaneous repair of CTS and cardiac anomalies. All patients were operated on through a median sternotomy and with cardiopulmonary bypass (CPB).

\section{Patients and Methods}

Between January 2000 and December 2003, 9 infants underwent surgical repair of a CTS and congenital heart disease at the Department of Cardiac Surgery, University of Heidelberg. There were 4 male and 5 female patients. Age ranged from 1 to 9 months (median age, 4.3 months). All patients were approached through a median sternotomy with the use of CPB (Table 1).

The intraoperative findings revealed localized tracheal stenosis in 3 patients. Funnel-type tracheal stenosis was observed in 6 patients. Histology of the stenotic area revealed the cartilaginous rings to be completely encircling the trachea.

Associated cardiac anomalies included ostium secundum ASD in 5 patients and VSD in 2 patients, PA sling in 4 patients, patent ductus arteriosus in 6 patients, AVSD in 1 patient, aortic arch hypoplasia in 1 patient, coarctation of the aorta in 1 patient, and partial anomalous pulmonary venous connection in 2 patients, one of them with scimitar syndrome. Tracheal origin of the right upper lobe was diagnosed in 2 of the patients. In another 2 patients tracheoesophageal fistula was diagnosed as an associated anomaly. A right aberrant subclavian artery (lusoria) was found in 1 patient.

Previous operations (elsewhere) included correction of coarctation in 1 patient, esophageal atresia type III in 2 patients, closure of the persistent arterial duct and PA banding in 1 patient, and translocation of the left pulmonary artery (LPA) in 1 patient with
PA sling. Preoperatively all 9 patients were long-term respirator dependent. All patients received diagnoses preoperatively by means of tracheobronchoscopy. Actual angiography with concomitant tracheobronchography was performed to diagnose simultaneously tracheal and cardiovascular pathology. Correction of cardiac defects or vascular sling during CPB was followed by tracheal resection and end-to-end anastomosis. In 2 of the patients, a modified tracheal bronchial reconstruction was necessary. The malacic parts of the carina, together with the proximal part of the bronchi, were resected. The carina was reconstructed by suturing together both main-stem bronchi. An end-to-end tracheal anastomosis was then carried out between the neocarina and the proximal trachea. Tracheal resection and anastomosis were performed and guided by intraoperative video-documented bronchoscopy.

\section{Selected Case Histories}

Case 1. A male infant, 3 months of age and weighing $5000 \mathrm{~g}$, was referred to our hospital with CTS with complete cartilaginous O-rings (funnel-type trachea), ASD, and scimitar syndrome. For this patient, we elected to perform the complete repair in one stage. Repair was performed through a midline sternotomy with the use of CPB. The intrathoracic part of the trachea, including the carina and the proximal segments of the main bronchi, were mobilized. To preserve circulation, the airway was not circumferentially mobilized for more than $1 \mathrm{~cm}$ beyond the resection margin. Pulmonary ligaments in both sides were transected. Both pulmonary hiluses, including pulmonary veins, were dissected free. A partial right pulmonary vein anomalous drainage through the scimitar vein connection to the inferior vena cava on the level of the diaphragm was detected. CPB was initiated, and the child was cooled to $24^{\circ} \mathrm{C}$. The aorta was crossclamped, and cold crystalloid antegrade cardioplegia (Bretschneider) was instituted. During circulatory arrest, the scimitar vein was detached from the inferior vena cava, mobilized, and anastomosed end-to-side with the left atrium. Fossa ovalis-type ASD was closed with direct continuous suture. Deairing of the heart and beginning of CPB followed (duration of the circulatory arrest was 20 minutes). With the heart beating, the tracheal tube was removed. The limits of the tracheal stenosis were recognized under bronchoscopic control. The stenotic segment of the trachea, $18 \mathrm{~mm}$ in length, with circular rings, an extremely edematous mucosa, and an inner diameter of $4 \mathrm{~mm}$, was resected. Both ends of the trachea after additional mobilization were approximated together and anastomosed free of tension and end-to-end with interrupted 4.0 polydioxanone suture. The intraoperative bronchoscopic control showed no residual obstruction of the reconstructed trachea. CPB was discontinued at stable hemodynamics, sinus rhythm, and normothermy. Central venous pressure was $12 \mathrm{~mm} \mathrm{Hg}$. Arterial pressure was 80/45 mm Hg (mean, 60 $\mathrm{mm} \mathrm{Hg}$ ). Arterial $\mathrm{Po}_{2}$ was $240 \mathrm{~mm} \mathrm{Hg}$ at a fraction of inspired oxygen of 0.6.

Case 2. A female infant 1.5 months of age was referred to our unit after repair of coarctation of the aorta elsewhere. The patient's diagnosis preoperatively was VSD, ASD, hypoplasia of the aortic isthmus, pulmonary sling syndrome, and tracheal stenosis of the funnel type (Figure 1). We decided to perform complete repair of cardiac and tracheal malformations with CPB simultaneously. The heart was exposed through a median sternotomy. CPB was carried out with ascending aortic and right atrial cannulation. A cooling 
TABLE 1. Patients with tracheal stenosis and congenital cardiac malformations operated on between 2000 and 2003

\begin{tabular}{|c|c|c|c|c|}
\hline Patient & Tracheal pathology & Cardiovascular pathology & Surgical procedure & LRT \\
\hline Male, 5 mo & Funnel trachea, TM & PA sling, PDA & $\begin{array}{l}\text { Segm. TR E-E, PDA lig., } \\
\text { reimplantation of LPA }\end{array}$ & $2.5 \mathrm{~cm}$ \\
\hline Female, 3 mo & Funnel trachea & AVSD, St. post PDA lig, PAB & Segm. TR E-E, AVSD correction & $2.7 \mathrm{~cm}$ \\
\hline Female, $6 \mathrm{mo}$ & $\begin{array}{l}\text { Tracheal stenosis, TM carina, St. } \\
\text { post OP-tracheoesophageal } \\
\text { fistula }\end{array}$ & PDA & $\begin{array}{l}\text { Segm. TR E-E, plastic } \\
\text { reconstruction of the carina, } \\
\text { PDA lig., ECMO }\end{array}$ & $2.5 \mathrm{~cm}$ \\
\hline Male, 5 mo & $\begin{array}{l}\text { Funnel trachea, partial TM, tracheal } \\
\text { diverticulum, tracheal origin of } \\
\text { the right upper lobe }\end{array}$ & $\begin{array}{l}\text { St. post OP-PA sling, LPA stenosis, } \\
\text { ostium secundum ASD }\end{array}$ & $\begin{array}{l}\text { Segm. TR E-E, right upper } \\
\text { lobectomy, reimplantation of } \\
\text { LPA, PFO closure }\end{array}$ & $2.4 \mathrm{~cm}$ \\
\hline Male, 3 mo & Funnel trachea & $\begin{array}{l}\text { Ostium secundum ASD, } \\
\text { PAPVC-scimitar syndrome }\end{array}$ & $\begin{array}{l}\text { Segm. TR E-E, PAPVC repair, } \\
\text { ASD closure }\end{array}$ & $1.8 \mathrm{~cm}$ \\
\hline Female, $6 \mathrm{mo}$ & Funnel trachea & $\begin{array}{l}\text { Arteria lusoria (tracheal and } \\
\text { esophageal compression), ostium } \\
\text { secundum ASD, PDA }\end{array}$ & $\begin{array}{l}\text { Segm. TR E-E, reimplantation of } \\
\text { aberrant subclavian artery, } \\
\text { PFO closure, PDA lig. }\end{array}$ & $1.2 \mathrm{~cm}$ \\
\hline Female, 9 mo & $\begin{array}{l}\mathrm{TM} \text {, tracheal origin of the right } \\
\text { upper lobe, St. post } \\
\text { OP-tracheoesophageal fistula }\end{array}$ & PAPVC, PDA & $\begin{array}{l}\text { Segm. TR E-E, PAPVC repair, } \\
\text { PDA lig. }\end{array}$ & $1.8 \mathrm{~cm}$ \\
\hline Male, 1 mo & Tracheal stenosis, TM carina & $\begin{array}{l}\text { PA sling, ostium secundum ASD, } \\
\text { VSD, PDA }\end{array}$ & $\begin{array}{l}\text { Segm. TR E-E, tracheobronchial } \\
\text { reconstruction, VSD closure, } \\
\text { ASD closure, Reimplantation } \\
\text { of LPA, PDA lig. }\end{array}$ & $2.2 \mathrm{~cm}$ \\
\hline Female, $1.5 \mathrm{mo}$ & Funnel trachea & $\begin{array}{l}\text { VSD, ostium secundum ASD, PA } \\
\text { sling, hypoplastic aortic arch, St. } \\
\text { post OP-PDA lig., CoA repair } \\
\text { (E-E) }\end{array}$ & $\begin{array}{l}\text { Segm. TR E-E, tracheobronchial } \\
\text { reconstruction, VSD closure, } \\
\text { ASD closure, reimplantation } \\
\text { of LPA, patch repair of the } \\
\text { aortic arch }\end{array}$ & $2.5 \mathrm{~cm}$ \\
\hline
\end{tabular}

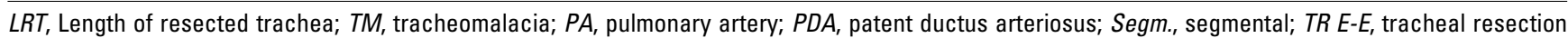
and end-to-end anastomosis; lig., ligation; $L P A$, left pulmonary artery; $A V S D$, atrioventricular septal defect; St. post, status post; $P A B$, pulmonary artery banding; ECMO, extracorporeal membrane oxygenation; $O P$, operation; $A S D$, atrial septal defect; $P F O$, patent foramen ovale; $P A P V C$, partial anomalous pulmonary venous connection; $V S D$, ventricular septal defect; $C O A$, coarctation of the aorta; $E-E$, end-to-end anastomosis.

down to deep hypothermic $\left(18^{\circ} \mathrm{C}\right)$ circulatory arrest was performed. During the cooling phase, the aorta ascendens, arch, descendens, and PAs were extensively mobilized. The aorta after the origin of the left carotid artery was hypoplastic on short distance, with an external diameter of $4 \mathrm{~mm}$. The LPA originated from the right $\mathrm{PA}$, had a retrotracheal course, and was compressing the carina and the distal tracheal region. The LPA was reimplanted end-to-side in the orthotopic position in the main PA. During deep hypothermic circulatory arrest, the aortic arch was opened longitudinally and enlarged with an autopericardial patch treated with glutaraldehyde. Perimembraneous VSD and secundum ASD were then closed with autopericardial patches. Deairing of the heart and beginning of CPB followed. The whole intrathoracic part of the trachea and both main bronchi were additionally mobilized after declamping of the aorta. The pulmonary ligaments were transected. Macroscopically the whole visible part of the trachea and proximal segments of both bronchi showed signs of tracheomalacia. The trachea was resected distally at the level of the carina: the inner diameter was $3 \mathrm{~mm}$, and the mucosa showed inflammatory changes. The malacic parts of the carina were resected together with the proximal part of the right main bronchus. The trachea was resected cranially at an overall distance of $2.5 \mathrm{~cm}$ under bronchoscopic control. Once resection margins were

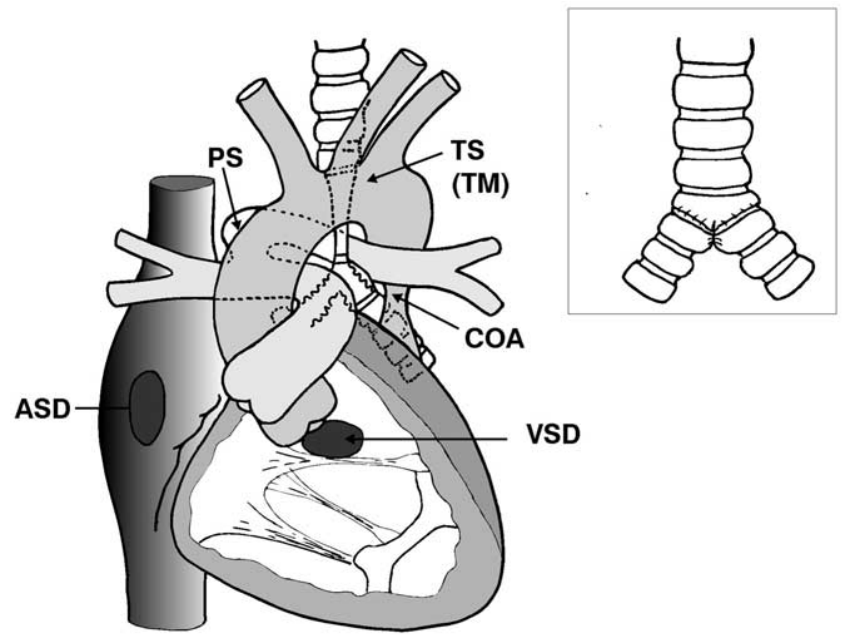

Figure 1. Schematic illustration showing ventricular septal defect (VSD), atrial septal defect (ASD), hypoplasia of the aortic isthmus, pulmonary sling syndrome, and funnel-type tracheal stenosis in patient 2. PS, Pulmonary sling; TS (TM), tracheal stenosis (tracheomalacia); COA, coarctation of the aorta. 
deemed adequate, reconstruction of the tracheobronchial tree was carried out. The carina was reconstructed bringing the medial walls of both main-stem bronchi together with interrupted sutures. An end-to-end tracheal anastomosis was then carried out between the newly formed carina and the proximal trachea with interrupted sutures. The final bronchoscopic examination showed no signs of obstruction. Central venous pressure was $11 \mathrm{~mm} \mathrm{Hg}$. Arterial pressure was 95/50 mm $\mathrm{Hg}$ (mean, $67 \mathrm{~mm} \mathrm{Hg}$ ). $\mathrm{Po}_{2}$ was $140 \mathrm{~mm}$ $\mathrm{Hg}$ at a fraction of inspired oxygen of 1.0.

\section{Results}

There was no operative mortality. One child died 6 weeks postoperatively. The patient had been operated on for PA sling, VSD, tracheal stenosis (funnel-type trachea), and severe tracheomalacia at the carinal region. He had renal insufficiency early postoperatively, which was treated with peritoneal dialysis. The patient had mediastinitis caused by anastomotic dehiscence in the later postoperative course, which was treated conservatively with antibiotics. The dehiscence was diagnosed with an urgent bronchoscopy. The child died with a clinical picture of sepsis and disseminated intravascular coagulation.

None of the patients required tracheostomy. All of the patients underwent echocardiography to confirm the adequacy of the congenital cardiac surgical repair. The patency of the reimplanted LPA in the PA sling was also followed by means of echocardiographic examinations. None of the patients were rehospitalized in the postoperative period.

Eight patients were extubated between the 14th and 30th postoperative days under bronchoscopic monitoring. The mean intubation time after airway repair was 20.6 days. The extubation was performed after a stepwise respirator-weaning program. The endoscopic examination before the patients were discharged showed adequate airway dimensions and patency in every case. The midterm results after a mean follow-up of 37 months (range, 16-58 months) for the entire group demonstrate a very stabile and complication-free clinical outcome.

\section{Discussion}

CTS from complete tracheal rings (funnel-type trachea) represents a rare and challenging group of patients. Infants born with complete cartilage tracheal rings have life-threatening respiratory distress as a leading clinical symptom.

The most common pathologic finding is an absence of the normal membranous part of the trachea, and at the site of the complete rings, the tracheal lumen is often only 2 to $3 \mathrm{~mm}$. Medical management is associated with at least $40 \%$ mortality. ${ }^{8}$ Surgical repair, however, represents the mainstay of therapy and is associated with low mortality and initially good anatomic and functional results. ${ }^{2}$

Associated congenital heart disease is diagnosed often in this group of patients, mostly VSD and ASD. Some of the more complicated congenital heart malformations can also accompany CTS: AVSDs, tetralogy of Fallot, and scimitar syndrome. CTS often is associated with pulmonary vascular sling or bronchus suis, an anomalous right upper bronchus branching from the trachea. ${ }^{9}$

The concomitant surgical repair of CTS and complex cardiac anomalies in infants is thought to carry a higher risk of morbidity and mortality. ${ }^{10}$ Nevertheless, from a pathophysiologic point of view, it seems more reasonable to repair both the tracheal and cardiac pathology simultaneously. Pathologic hemodynamics in addition to obstruction of a small-dimension airway, with its known particular mucosal reactivity, leave very low margins for compensatory mechanisms, especially in respiratory tract infections. ${ }^{11}$

Surgical intervention for the combination of an obstructive lesion of the intrathoracic trachea and complex congenital heart disease in a staged fashion has been accompanied by a grave prognosis because the presence of the other untreated lesion usually creates difficult problems in postoperative management. ${ }^{12}$ When one gives priority to the repair of the cardiac lesion, the patient usually has severe and often fatal respiratory trouble in the postoperative period because of the obstructive lesion of the trachea. When the tracheal lesion is repaired first, the postoperative risk of wound dehiscence and infection increases because of impaired microcirculation or hypoxia (or both) of the tissue and malnutrition because of persistence of the cardiac lesion. ${ }^{10}$ From these viewpoints, it seems indispensable to perform effective surgical relief of both disease entities concomitantly to obtain better operative results.

Therefore we attempted simultaneous repair of tracheal stenosis at the time of surgical intervention on congenital cardiac lesions in 9 patients. Preoperatively we preferred the relatively high diagnostic accuracy of angiography with concomitant tracheobronchography because by using this, both involved organ systems can be visualized. ${ }^{9}$

All patients were operated on with the aid of CPB. The cardiac lesions in our patients were as follows: ostium secundum ASD in 5 patients and VSD in 2 patients, PA sling in 4 patients, patent ductus arteriosus in 6 patients, AVSD in 1 patient, aortic arch hypoplasia in 1 patient, coarctation of the aorta in 1 patient, and partial anomalous pulmonary venous connection in 2 patients, one of them with scimitar syndrome.

Tracheal origin of the right upper lobe was diagnosed in 2 of the patients. In another 2 patients tracheoesophageal fistula was diagnosed as an associated anomaly. A right aberrant subclavian artery (lusoria) was present in 1 patient.

We performed primary tracheal reconstruction with end-toend anastomosis in all patients undergoing surgical intervention. The crucial part of our surgical technique regarding the tracheal part of the operation is careful dissection and mobilization of the trachea, main bronchi, PAs, and veins to obtain tension-free tracheal anastomosis. We emphasize the 
intraoperative use of endoscopic monitoring of the airways. ${ }^{10}$ This permits careful exploration to identify residual tracheal stenosis and facilitates clearing of secretions at the end of the operation.

None of the patients required reoperation for either residual or recurrent tracheal stenosis.

In conclusion, we advocate our current strategy for infants with CTS: resection with end-to-end anastomosis and simultaneous repair of associated intracardiac anomalies.

\section{References}

1. Wright CD, Graham BB, Eng M, et al. Paediatric tracheal surgery. Ann Thorac Surg. 2002;74:308-14.

2. Dodge-Khatami A, Tsang VT, Roebuck DJ, et al. Management of congenital tracheal stenosis: a multidisciplinary approach. Images Paediatr Cardiol. 2000;2:29-39.

3. Backer CL, Mavroudis C. Congenital Heart Surgery Nomenclature and Database Project: vascular rings, tracheal stenosis, pectus excavatum. Ann Thorac Surg. 2000;69(suppl):S308-18.

4. Grillo HC, Wright CD, Vlahakes GJ, MacGillivray TE. Management of congenital tracheal stenosis by means of slide tracheoplasty or resection and reconstruction, with long-term follow-up of growth after slide tracheoplasty. J Thorac Cardiovasc Surg. 2002;123:145-52.

5. Backer CL, Mavroudis C, Dunham ME, Holinger LD. Pulmonary artery sling: results with median sternotomy, cardiopulmonary bypass, and reimplantation. Ann Thorac Surg. 1999;67:1738-45.

6. Backer CL, Mavroudis C, Gerber ME, Holinger L. Tracheal surgery in children: an 18-year review of four techniques. Eur J Cardiothorac Surg. 2001;19:777-84.

7. Hagl S, Jakob H, Sebening Ch, et al. External stabilization of longsegment tracheobronchomalacia guided by intraoperative bronchoscopy. Ann Thorac Surg. 1997;64:1412-20.

8. Benjamin B, Pitkin J, Cohen D. Congenital tracheal stenosis. Ann Otol Rhinol Laryngol. 1981;90:364-71.

9. Loukanov TS, Sebening Ch, Springer W, Hagl S. A case of pulmonary artery sling associated with long-segment funnel trachea and bronchus suis. Ann Thorac Surg. 2004;78:1839-42.

10. Yamaguchi M, Oshima Y, Hosokawa Y, et al. Concomitant repair of congenital tracheal stenosis and complex cardiac anomaly in small children. J Thorac Cardiovasc Surg. 1990;100:181-7.

11. Sebening Ch, Jakob H, Tochtermann U, et al. Vascular tracheobronchial compression syndromes-experience in surgical treatment and literature review. Thorac Cardiovasc Surg. 2000;48:164-74.

12. Nakayama DK, Harrison M, de Lorimier AA, Brasch RC, Fishman NH. Reconstructive surgery for obstructive lesions of the intrathoracic trachea in infants and small children. J Pediatr Surg. 1982;17:854-68.

\section{ON THE MOVE?}

Don't miss a single issue of the journal! To ensure prompt service when you change your address, please photocopy and complete the form below.

Please send your change of address notification at least six weeks before your move to ensure continued service. We regret we cannot guarantee replacement of issues missed due to late notification.

\section{JOURNAL TITLE:}

Fill in the title of the journal here.

\section{OLD ADDRESS:}

Affix the address label from a recent issue of the journal here.

\section{NEW ADDRESS:}

Clearly print your new address here.

Name

Address

City/State/ZIP
COPY AND MAIL THIS FORM TO:

Elsevier Inc.

Subscription Customer Service

6277 Sea Harbor Dr

Orlando, FL 32887
OR FAX TO:

407-363-9661

OR E-mail:

elspcs@elsevier.com
OR PHONE:

800-654-2452

Outside the U.S., call

407-345-4000 